\title{
PREVALENCE AND CLINICAL CONSEQUENCES OF POLYPHARMACY ON MEDICATION PROFILE AMONG THE ELDERLY IN A TERTIARY CARE TEACHING HOSPITAL
}

\author{
LAKSHMI PRASANNA MN ${ }^{1 *}$, AZIZ UNNISA ${ }^{2}$ \\ ${ }^{1}$ Department of Pharmacy Practice, Vijaya Institute of Pharmaceutical Sciences, Andhra Pradesh, India. ${ }^{2}$ Department of Pharmaceutical \\ Chemistry, University of Hail, Hail, Saudi Arabia. Email:prassy89@gmail.com
}

Received: 01 March 2020, Revised and Accepted: 14 April 2020

\section{ABSTRACT}

Objective: A sharp increase in chronic diseases for elderly patients has been observed in recent years resulting in polypharmacy, which may lead to drug-drug interactions (DDI's), drug-related problems, adverse drug reactions (ADR's), and many more issues in these patients. The present study was conducted to assess the clinical consequences of polypharmacy and its prevalence in the older adult population.

Methods: Our work is a prospective, observational study carried out in a tertiary care teaching hospital. The polypharmacy prescriptions were identified (taking at least five medications), and drug-drug interactions were detected by Micromedex ${ }^{\circledR}$ DrugReax ${ }^{\circledR}$ System 2.0 version. The medication profiles were also checked for inappropriate prescribing according to Beers Criteria 2015.

Results: In the study, the mean age of patients was found to be $72.4 \pm 8.8$ years. Most of the patients (81.8\%) had more than two and less than five diseases. The mean number of drugs prescribed in all the prescriptions was found to be 7.4 \pm 2.6 . According to Beers Criteria-2015, 3.83\% of the total medications prescribed were inappropriate, $74.1 \%$ of moderate DDI's were observed in patients, and $50.2 \%$ of the DDI's observed theoretically were documented as fair.

Conclusion: The impact of polypharmacy on consequences such as the length of stay, DDI's, and DRP's was also found to be significant. This study concludes that the medication profile of older adult patients should be assessed regularly for the rationality of drug therapy to maximize the therapeutic response positively with the lowest number of medications possible.

Keywords: Older adults, Polypharmacy, Drug-related problems, Beer's Criteria.

(c) 2020 The Authors. Published by Innovare Academic Sciences Pvt Ltd. This is an open access article under the CC BY license (http://creativecommons. org/licenses/by/4. 0/) DOI: http://dx.doi.org/10.22159/ajpcr.2020.v13i6.37623

\section{INTRODUCTION}

Providing rational health care is defined as treating the disease following the therapy guidelines, which often implies treatment with multiple pharmacological and non-pharmacological therapies, one of the impending outcomes of which is polypharmacy. Polypharmacy is defined as the use of various medications at the same time that is clinically indicated, resulting in unnecessary therapy [1]. Polypharmacy is seen in geriatric patients, patients with multiple comorbidities, and terminal illness. Other factors include multiple prescribers, poor compliance, and lack of education [2].

The prevalence of polypharmacy is $5-78 \%$ has been reported, the figure having quintupled with an aging population between 2000 and 2010 [3]. Elderly patients are the people more vulnerable to polypharmacy because, as a group, they take more drugs than other young population due to multiple comorbidities. They are also known to be at risk of the side effects because of age-associated reduction in physiological capacity or increased stress [2]. In India, the older adults (aged 65 years or above) account for $7 \%$ of the total population. According to the Indian Census 2011, the population of elderly persons in India was nearly 104 million, 51 million males and 53 million females. The prevalence of polypharmacy was $25,20 \%$ more among the older men (26.10\%) than women (24.20\%) in India [2].

Polypharmacy results in adverse drug interactions, which are a significant risk to the quality of the life of the patients as some of them may pose a life-threatening risk [4]. The ADRs are considered as symptoms of another disease and treated, which again results in polypharmacy. In a population-based study, an $88 \%$ increased risk of experiencing an ADE was reported in outpatients taking five or more medications as compared to those who were taking a smaller number of medicines [5].

Polypharmacy is a major issue and requires extensive research on the methods primary care providers utilize to assess polypharmacy. This study focuses on interventions to improve the optimal use of medication in the older adult population, which have increased risk due to ADRs and drug-drug interactions.

\section{MATERIALS AND METHODS}

The first phase of the study included the review of the literature using the relevant terms such as polypharmacy, impact, geriatric, inappropriate dosing, Beers' Criteria 2015 [6], medication appropriateness index [7]. Various sources were reviewed, and all the discreet factors were noted.

A prospective observational study in the elderly was developed, approved by the Institutional Ethics Committee, and conducted in a tertiary care teaching hospital from January 1 to June 30,2017 . The patients were reviewed, and those included in this study were of age $>65$ and taking more than two prescription and OTC medications. Terminally ill patients were excluded as it is inevitable to use multiple drugs for long-term medical goals in such cases.

All the necessary and relevant data were obtained by us from prospective series of in-patient case records, treatment chart, patient history record, laboratory data reports, patient/caretaker interview regarding OTC medications, and other relevant data sources. A separate data entry format was designed by me for incorporating in-patient details. It included parameters such as demographic information, family history, medical history, laboratory investigations, diagnosis, categories 
and no. of drugs prescribed, no. of medical problems, drug interactions, and adverse drug reactions. The patients were followed by us until the date they were discharged.

The demographic data collected by our team included the patient's age, gender, and address. The current medication data included all the drugs, their dosage, route of administration, date of the drug started, and stopped. The medical and medication history data collected consist of the patient's previous allergies, comorbidities, and the drugs received previously. The laboratory data collected included the relevant laboratory investigations done to confirm the diagnosis, prognosis, and drug-drug interactions. All prescription or non-prescription drugs being taken by the patient were counted as a medication. In this study, we considered polypharmacy as the use of five or more medications regardless of whether they are necessary or unnecessary. Drug-drug interactions were identified using the Micromedex ${ }^{\circledR}$, DrugReax $^{\circledR}$ System 2.0 version, and the drug interactions found were noted in the patient's progress notes. The medication profiles were also checked for inappropriate prescribing, according to Beer's Criteria 2015 [6].

\section{Criteria for evaluation}

Approaches were developed based on the level of significance, which is based on severity, onset, and documentation. Onset is the time occurrence of the clinical effects of the interaction, which may be rapid $(<24 \mathrm{~h})$ or delayed $(>24 \mathrm{~h})$ or inaccurate. The severity is based on the potential of the effect occurring, i.e., minor (mild), moderate (serious), and severe (life-threatening). Documentation is based on the availability of data and classified as unlikely, poor, fair, good, and excellent.

\section{Statistical analysis}

The SPSS (Statistical Package for the Social Sciences incorporated, Version 20) for windows was used for carrying out statistical analysis. Data were summarized as the mean and standard deviation (SD) or number and percentage, as appropriate. The association between exposure to polypharmacy and each independent variable was evaluated by calculating the odds ratio (OR) at $95 \% \mathrm{CI}$. A Chi-square test was applied for some of the parameters to prove their statistical significance using GraphPad prism 5 [7]. $\mathrm{p}<0.005$ was considered to be significant.

\section{RESULTS}

\section{Gender distribution}

During the study period, 274 patients were eligible for inclusion in the study. Of this number, 141 (51.45\%) were male, and 133 (48.50\%) were female. The mean for age was $62.4 \pm 8.8$ years, with a range of $50-89$ years.

\section{Age distribution}

The age distribution of enrolled patients is as follows, 98 (35.8\%) patients were between the age group of 65 and 69 years of age, $114(41.6 \%)$ were between the age group of 70 and 74 years, and $49(17.9 \%)$ were between the age group of 75 and 79 years. The remaining $13(4.8 \%)$ patients were $\geq 80$ years of age. Most of the patients were age around 70-74 years. The mean age among males was $73.6 \pm 9.1$ years, and among females, $71.2 \pm 8.3$

\section{Prevalence of diseases and drugs}

The patients enrolled in the study were mostly having more than two and less than five diseases (81.8\%). Patients have two conditions accounted for $36.9 \%$ in the total study population, while $4.4 \%$ had five or more diseases. The number of drugs most frequently prescribed was $7(17.9 \%)$, with the overall mean of $7.4 \pm 2.6$. Fig. 1 shows the number of diseases and drugs as a function of the percentage of patients.

\section{Polypharmacy and no. of patients}

The total number of 2035 drugs was prescribed among the 274 patients, and the average number of concurrently prescribed medications per patient was $7.43 \pm 2.63$. The average number of drugs received by male and female patients was $7.4 \pm 2.6$ and $7.5 \pm 2.7$, respectively. There was

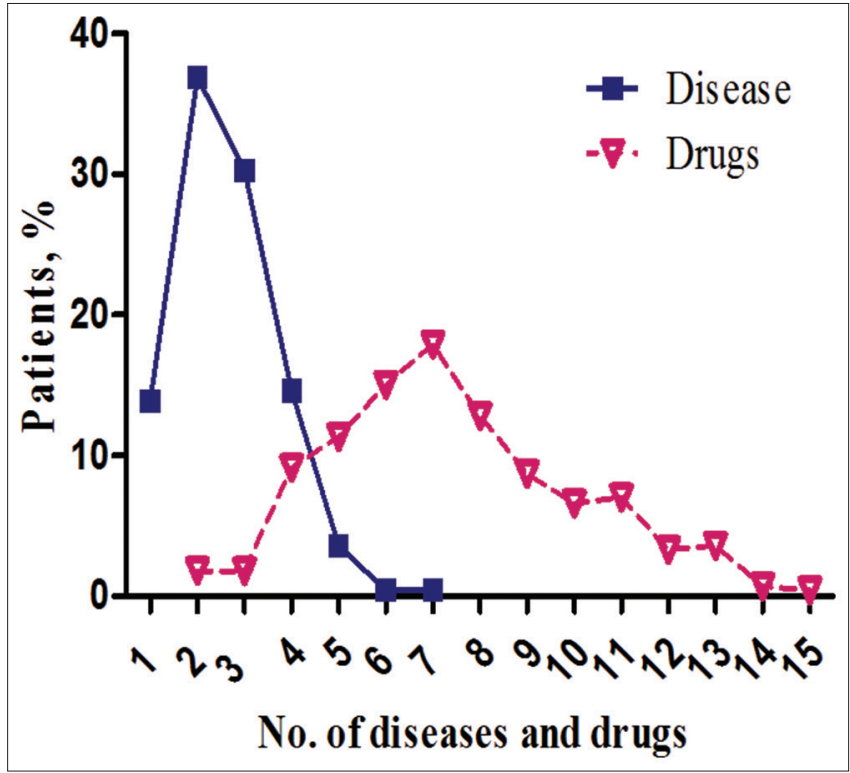

Fig. 1: Prevalence of diseases and drugs

a negligible difference between the genders in the mean number of medications prescribed concurrently during hospital stays. It was found that the maximum number of drugs prescribed for a single patient was 15 . In the study population, most of the patients $(65.7 \%)$ were taking five to nine drugs, following patients $(21.53 \%)$ were taking more than ten drugs and $12.8 \%$ of the patients were taking two to four drugs.

\section{Polypharmacy and gender}

Out of the study population 274, the number of patients using polypharmacy was 239 (87.2\%). The prevalence of polypharmacy among males was $87.4 \%$ and females was $86.4 \%$; this shows prevalence is slightly more in males when compared to females.

\section{Polypharmacy and age}

In a total of 274 patients enrolled in the study, 239 patients were prescribed with five and more drugs. In these 239 patients, 87 were in the age group of 65-69 years, 100 were in the age group of 70-74, and 41 were in the age group of 74-79. The remaining 11 patients were $\geq 80$ years of age.

\section{Polypharmacy and length of stay}

The mean length of stay of the 274 patients entering the study was found to be $6.4 \pm 3$.6. Polypharmacy was directly associated with the length of the hospital stay (5-9 days) $\left(\chi^{2}=31.30 ; p=0.0001\right)$.

\section{Sample characteristics}

Characteristics of the study patients, according to polypharmacy status, are given in Table 1. Out of the study population, 35 patients were given $<5$ drugs, 180 patients were given 5-9 drugs, and 59 patients were given $\geq$ ten drugs. The distribution of these patients based on gender, comorbidities, length of stay, residency, and no of drugs taken is given in Table 1.

\section{Disease wise distribution and categories of drugs prescribed}

The study population was admitted with a variety of diseases, complications, and comorbidities. The majority of the patients were diagnosed with hypertension, which is one of the most frequent diseases of older adults. The commonly prescribed medication classes in the study population are listed in Table 9. Cardiovascular drugs 375 (18.4\%), vitamins, minerals, and dietary supplements 285 (14\%), others $261(12.8 \%)$ were the frequently prescribed drug classes. Polypharmacy among various drug classes was observed. It was a maximum of $99 \%$ in drugs acting on the respiratory system, followed by $98.5 \%$ in drugs effect on the endocrine system, followed by diabetes (Table 2). 
Table 1: Sample characteristics according to polypharmacy status

\begin{tabular}{|c|c|c|c|c|}
\hline Variables of interest & All $(n=274)$ & $\begin{array}{l}\text { No. polypharmacy } \\
(<5 \text { drugs; } n=35)\end{array}$ & $\begin{array}{l}\text { Polypharmacy } \\
\text { (5-9 drugs; } n=180 \text { ) }\end{array}$ & $\begin{array}{l}\text { Excessive polypharmacy } \\
(\geq 10 \text { drugs; } n=59)\end{array}$ \\
\hline \multicolumn{5}{|l|}{ Demographics } \\
\hline Age, y; mean $\pm S D$ & $62.4 \pm 8.8$ & $63.2 \pm 9.7$ & $62.7 \pm 8.7$ & $61.1 \pm 8.3$ \\
\hline Female gender, $\mathrm{n}(\%)$ & $133(48.5)$ & $18(51.4)$ & $87(48.3)$ & $28(47.4)$ \\
\hline Male gender, n (\%) & $141(51.4)$ & $17(48.6)$ & $93(51.7)$ & $31(52.5)$ \\
\hline \multicolumn{5}{|l|}{ Co morbidities } \\
\hline No. of diseases, mean \pm SD & $2.6 \pm 1.1$ & $2 \pm 0.8$ & $2.6 \pm 1.0$ & $3.05 \pm 1.2$ \\
\hline 1-5 days & 132 & 24 & 61 & 15 \\
\hline $6-10$ days & 114 & 10 & 106 & 30 \\
\hline$>10$ days & 28 & 1 & 13 & 14 \\
\hline \multicolumn{5}{|l|}{ Residency } \\
\hline Urban & 52 & 9 & 20 & 23 \\
\hline Semi-urban & 73 & 15 & 37 & 21 \\
\hline Rural & 149 & 11 & 123 & 15 \\
\hline \multicolumn{5}{|l|}{ No. of drugs taken } \\
\hline Female $(n=133)$ & $7.5 \pm 2.7$ & $3.4 \pm 0.9$ & $7.03 \pm 1.4$ & $11.4 \pm 1.3$ \\
\hline
\end{tabular}

Table 2: Disease wise distribution and categories of drugs prescribed

\begin{tabular}{|c|c|c|c|}
\hline Diseases & No. of patients (frequency) (\%) & Category of drugs acting on & Number of drugs (\%) \\
\hline Hypertension & $121(44.16)$ & Respiratory system & $88(4.3)$ \\
\hline Type II diabetes mellitus & $100(36.5)$ & Antimicrobial drugs & $253(12.4)$ \\
\hline COPD/asthma & $26(9.5)$ & Gastrointestinal system & $235(11.5)$ \\
\hline Cerebrovascular accident & $21(7.7)$ & Cardiovascular drugs & $375(18.4)$ \\
\hline Chronic kidney disease & $24(8.7)$ & Endocrine system & $199(9.8)$ \\
\hline Hemiparesis & $25(9.1)$ & Hematological system & $111(5.5)$ \\
\hline Acute gastroenteritis & $12(4.4)$ & Analgesics and anti-inflammatory drugs & $138(6.8)$ \\
\hline Congestive cardiac failure & $18(6.6)$ & Vitamins, minerals and dietary supplements & $285(14)$ \\
\hline Dilated cardiomyopathy & $13(4.7)$ & Others & $261(12.8)$ \\
\hline Ischemic heart disease & $23(8.4)$ & & \\
\hline Left ventricular failure & $8(3.0)$ & & \\
\hline Diabetic nephropathy & $11(4.01)$ & & \\
\hline Ischemic cardiomyopathy & $7(2.55)$ & & \\
\hline Anemia & $19(7.0)$ & & \\
\hline
\end{tabular}

COPD:

Table 3: Influence of the polypharmacy on drug-drug interactions

\begin{tabular}{llll}
\hline $\begin{array}{l}\text { No. of drugs } \\
\text { concurrently } \\
\text { prescribed }\end{array}$ & $\begin{array}{l}\text { No. of } \\
\text { patients } \\
\text { receiving }\end{array}$ & $\begin{array}{l}\text { Patients with at } \\
\text { least one drug- } \\
\text { drug interaction }\end{array}$ & \\
\hline 2 & 5 & 1 & 20 \\
3 & 5 & 0 & 0 \\
4 & 25 & 8 & 32 \\
5 & 31 & 12 & 38.7 \\
6 & 41 & 19 & 46.3 \\
7 & 49 & 27 & 55.10 \\
8 & 35 & 23 & 65.71 \\
9 & 24 & 19 & 79.16 \\
10 & 18 & 17 & 94.4 \\
11 & 19 & 15 & 78.9 \\
12 & 9 & 7 & 77.7 \\
13 & 10 & 9 & 90 \\
14 & 2 & 2 & 100 \\
15 & 1 & 1 & 100 \\
\hline
\end{tabular}

\section{Inappropriate prescribing}

According to Beers Criteria 2015, it was revealed that $3.83 \%$ of the total drugs prescribed were inappropriate, $75(27.4 \%)$ patients received a potentially inappropriate prescription of at least one drug.
The occurrence of DDI's

Of the sampled population, 160 (58.4\%) had DDI's, and the frequency of DDI's per patient ranged from 1 to 9 . In this study, 15 cases of DDI's with significant severity were due to the combination of fluoroquinolones with antidiabetic drugs.

\section{Duration of onset}

Based on the probable time required for the drug-drug interactions to produce a reaction, these interactions were classified as rapid, delayed, and not specified. It was seen that a great majority of interactions were delayed interactions, accounting for 155 (38.2\%) of the interactions, while for $122(30 \%)$ of the interactions, the duration of onset was not specified.

\section{The severity of DDI's}

Based on the severity, the interactions were classified into three groups: Minor, moderate, and major. Of them, 19 (4.7\%) were potentially minor, $301(74.1 \%)$ of moderate, and $86(21.2 \%)$ of major severity.

\section{Documentation of DDI's}

Based on the documentation, the interactions were classified into three groups: Excellent, good, and fair. Interactions of excellent documentation accounted for $44(10.8 \%)$ of the study population, while those of good and fair documentation accounted for $204(50.2 \%)$ and 158 (39\%), respectively. 
Influence of polypharmacy on drug-drug interactions

The patients prescribed with several concurrent drugs are shown in Table 4. It has been observed as the number of drugs getting increased, the patient number got decreased, and hence, there is a progressive decline in patients taking more than 11 drugs. Table 3 shows that even though the patients taking more than 13 drugs are less in number, they have $100 \%$ DDI's.

\section{Drug-related problems identified}

Among 274 patients, 239 patients were observed with polypharmacy. The total number of drugs used in these 239 patients was 1910 . The present study revealed 504 drug-related problems. While $97.07 \%$ of polypharmacy patients had one or more drug-related issues, 42 patients were problem-free. Of 504 drug-related problems, $499(0.26 \%)$ were directly coupled to a prescribed drug, and five were classified as the need for additional drug or need for review.

\section{DDI's resulting in ADRs}

Out of the 160 patients with potential DDI's three patients $(1.9 \%$ of patients with potential DDI's and $1.1 \%$ of the total number of the patients) experienced three ADRs caused by three DDI's (Table 4).

\section{Comparison between patients with and without polypharmacy} The prevalence of polypharmacy among all participants was found to be $87.2 \%$. Table 5 shows the univariate analysis of polypharmacy-associated factors in relation to the demographic and clinical characteristics of the participants. It appeared that there was no statistically significant association between demographic characteristics and the prevalence of polypharmacy.

Role of polypharmacy as a predictor of DDI's, ADR's, and DRP's There was a substantial association between polypharmacy and the consequences such as drug-drug interactions, and drug-related problems, which are shown in Table $6(\mathrm{p}<0.0001)$. Clinically only three DDI's induced ADR's were observed.

\section{DISCUSSION}

A decline in physiological reserve in organs makes the elderly population develop some kinds of diseases and have more complications from mild problems [8]. Hazards of using multiple drugs in the elderly have been well recognized and include frailty, disability, and mortality and fall in the elderly [9]. In the present study, the majority of the patient population were males (51.45) than females. In a similar survey conducted, males were having a high incidence of polypharmacy than females [10], although females are more vulnerable.

Among the patient population of our study, the mean age of the patients was found to be $72.4 \pm 8$.8. Polypharmacy and polypathology are frequent among the elder group and record a 33\% excess polypharmacy [11].

Most of the patients in this study got admitted to the hospital with more than two and less than five diseases (81.8\%). Similar research conducted by Mizokami et al. on polypharmacy with common diseases in hospitalized elderly patients had shown that most of the patients who got admitted in their study were having a minimum of nine diseases [12]. Some characteristics of patients might justify polypharmacy. Diabetes and cerebrovascular diseases have been associated with polypharmacy [13]. In Registro Politepri SIMI, in Italian internal medicine coronary heart disease, heart failure, COPD is independently associated with polypharmacy. In our case, they accounted for $23 \%, 18 \%$, and $26 \%$ to polypharmacy, respectively.

The mean length of the stay of patients who were enrolled in the present study was found to be $6.4 \pm 3.6$ days. Polypharmacy was directly associated with the length of the hospital stay (5-9 days) $\left(\chi^{2}=31.30\right.$; $\mathrm{p}=0.0001$ ). This was in confirmation with similar studies conducted by Nobili et al. on the association between clusters of diseases and polypharmacy in hospitalized elderly patients [13], and Díez Mangano et al. [14] on patients with chronic obstructive pulmonary disease that concluded stating polypharmacy increased after hospitalization. The longer the stay greater, the polypharmacy was established [15].

In a total patient population of 274 patients, the mean of the drugs prescribed was found to be 7.4 \pm 2.6 . A similar study conducted among adult Saudi medical outpatients had shown that the average of the medicines prescribed was found to be $8.8 \pm 3.8$ [16]. In the present study, most of the patients $(65.7 \%)$ were taking five to nine drugs, following patients $(21.53 \%)$ were taking more than ten drugs and $12.8 \%$ of the patients were taking two to four drugs. In a total patient population of the present study, most of the patients were diagnosed with hypertension (44.16\%), followed by diabetes (36.5\%), and a tiny percentage of patients were diagnosed with ischemic cardiac myopathy (2.55).

In the present study, the majority $375(18.4 \%)$ of the drugs belong to the category of cardiovascular diseases, followed by vitamins, minerals, and dietary supplements 285 (14\%), and others 261 (12.8\%). The use of drugs concomitantly is also a prerequisite for establishing prescribing patterns and clinical associations.

The prescriptions of the patients participating in this study were also categorized based on the appropriateness of the medications prescribed according to the Beer's Criteria 2012 [6] method. In the present study, $3.83 \%$ of the total drugs were prescribed inappropriately. In some earlier studies conducted by Veena et al. on drug prescribing pattern in elderly patients and Ayesha et al. on polypharmacy leading to adverse drug reactions in elderly had shown that $4.33 \%$ and $2.37 \%$ of total drugs were prescribed in an inappropriate manner, respectively $[17,18]$.

Polypharmacy and excessive polypharmacy entail a risk of inappropriate medication [19] adverse drug-related effects and adverse health results [10,20-22]. Four hundred and six drug-drug Interactions were observed theoretically in 160 patients out of 274 patients, but clinically many of them were insignificant. Only three of DDI's induced ADR's (Atorvastatin+Fenofibrate, and Ramipril+Olmesartan, Calcium+Digoxin) were observed. The major interactions were observed between fluoroquinolones and anti-diabetic drugs (17.4\%).

It was observed in the present study that, as the number of drugs getting increased (more than 13), the patient number got decreased, and the incidence of drug-drug interactions were also increased. Among 274 patients, 239 patients were observed with polypharmacy. The total number of drugs used in these 239 patients was 1910. Of 504 drugrelated problems, $499(0.26 \%)$ were directly coupled to a prescribed

Table 4: Characterization of the ADR's that resulted from DDI's

\begin{tabular}{|c|c|c|c|c|c|c|}
\hline $\begin{array}{l}\text { Drug } \\
\text { combination }\end{array}$ & DDI mechanism & $\begin{array}{l}\text { Age (years)/ } \\
\text { gender }\end{array}$ & $\begin{array}{l}\text { No. of diagnoses/no. of } \\
\text { drugs/patient }\end{array}$ & $\begin{array}{l}\text { DDI } \\
\text { severity }\end{array}$ & $\begin{array}{l}\text { ADR resulting } \\
\text { from DDI }\end{array}$ & ADR consequence \\
\hline $\begin{array}{l}\text { Atorvastatin/ } \\
\text { fenofibrate }\end{array}$ & $\begin{array}{l}\text { Fenofibrate is a CYP2C9 } \\
\text { inhibitor }\end{array}$ & 68 years $/$ male & $4 / 4 / 1$ & Major & Myalgia & $\begin{array}{l}\text { Prolonged } \\
\text { hospitalization }\end{array}$ \\
\hline $\begin{array}{l}\text { Ramipril/ } \\
\text { olmesartan }\end{array}$ & $\begin{array}{l}\text { Dual blockade of the renin- } \\
\text { angiotensin-aldosterone system }\end{array}$ & 65 years/female & $3 / 8 / 1$ & Major & Hyperkalemia & Hospitalization \\
\hline Calcium/digoxin & Synergistic or additive effect & 71 years/female & $3 / 10 / 1$ & Major & Arrthymias & Hospitalization \\
\hline
\end{tabular}

ADR: Adverse drug reactions, DDI: Drug-drug interactions 
Table 5: Comparison between patients with and without polypharmacy

\begin{tabular}{|c|c|c|c|c|c|}
\hline Variables & All $n=274(100 \%)$ & $\begin{array}{l}\text { Non-polypharmacy } \\
\text { (1-4 drugs) } n=35(12.8 \%)\end{array}$ & $\begin{array}{l}\text { Polypharmacy ( } \geq 5 \text { drugs) } \\
n=239(87.2 \%)\end{array}$ & p-value & OR with CI \\
\hline \multicolumn{6}{|l|}{ Age (years) } \\
\hline $65-69$ & $98(35.77)$ & 11 & 87 & & Reference \\
\hline $70-74$ & $114(41.60)$ & 14 & 100 & 0.834 & $0.90(0.39-2.09)$ \\
\hline $75-79$ & $49(17.88)$ & 8 & 41 & 0.437 & $0.65(0.24-1.73)$ \\
\hline$\geq 80$ & $13(4.74)$ & 2 & 11 & 0.648 & $0.69(0.13-3.55)$ \\
\hline \multicolumn{6}{|l|}{ Gender } \\
\hline Male & $141(51.45)$ & 17 & 124 & 0.721 & $1.14(0.56-2.32)$ \\
\hline \multicolumn{6}{|l|}{ Residency } \\
\hline Urban & 52 & 9 & 43 & & Reference \\
\hline Semi-urban & 73 & 15 & 58 & 0.818 & $0.81(0.32-2.02)$ \\
\hline Rural & 149 & 11 & 138 & 0.06 & $2.63(1.02-6.76)$ \\
\hline \multicolumn{6}{|c|}{ No. of chronic diseases } \\
\hline$<4$ & 222 & 34 & 188 & & Reference \\
\hline$\geq 4$ & 52 & 1 & 51 & 0.0054 & $9.22(1.23-69.04)$ \\
\hline Hypertension & 121 & 8 & 113 & 0.796 & Reference \\
\hline Type II DM & 100 & 8 & 92 & 0.411 & $0.81(0.29-2.25)$ \\
\hline COPD/asthma & 26 & 3 & 23 & 0.02 & $0.54(0.13-2.2)$ \\
\hline Hemiparesis & 25 & 6 & 19 & 0.67 & $0.22(0.07-0.72)$ \\
\hline CKD & 24 & 2 & 22 & & $0.78(0.15-3.92)$ \\
\hline \multicolumn{6}{|c|}{ Disease load, mean (SD) } \\
\hline 1 Disease & 38 & 9 & 29 & & Reference \\
\hline 2 Disease & 101 & 18 & 83 & 0.474 & $1.43(0.58-3.54)$ \\
\hline 3 Diseases & 83 & 7 & 76 & 0.039 & 3.37 (1.15-9.89) \\
\hline 4 Diseases & 40 & 1 & 39 & 0.006 & $12.10(1.45-101)$ \\
\hline >5 Diseases & 12 & 0 & 12 & & \\
\hline \multicolumn{6}{|l|}{ Length of stay } \\
\hline $1-5$ days & 132 & 24 & 108 & & Reference \\
\hline 6-10 days & 114 & 10 & 104 & 0.041 & $2.31(1.05-5.07)$ \\
\hline$>10$ days & 28 & 1 & 27 & 0.081 & $6.0(0.78-46.37)$ \\
\hline
\end{tabular}

OR: Odds ratio, CI: Confidence interval, SD: Standard deviation, DM: Diabetes mellitus, COPD:

Table 6: Role of polypharmacy as a predictor of ddi's, ADR's and DRP's

\begin{tabular}{|c|c|c|c|c|c|c|}
\hline \multirow[t]{2}{*}{ Consequence } & \multicolumn{3}{|l|}{ No. of patients } & \multicolumn{3}{|c|}{ No. of problems identified } \\
\hline & $\begin{array}{l}\text { With } \\
\text { polypharmacy }\end{array}$ & $\begin{array}{l}\text { Without } \\
\text { polypharmacy }\end{array}$ & $\begin{array}{l}\text { p-value } \\
\left(\chi^{2} \text { test }\right)\end{array}$ & $\begin{array}{l}\text { With } \\
\text { polypharmacy }\end{array}$ & $\begin{array}{l}\text { Without } \\
\text { polypharmacy }\end{array}$ & $\begin{array}{l}\text { p-value } \\
\left(\chi^{2} \text { test }\right)\end{array}$ \\
\hline DDI’s & 151 & 9 & $<0.0001$ & 394 & 12 & $<0.0001$ \\
\hline ADR's & 2 & 1 & 0.564 & 2 & 1 & 0.564 \\
\hline DRP's & 223 & 9 & $<0.0001$ & 492 & 12 & $<0.0001$ \\
\hline
\end{tabular}

ADR: Adverse drug reactions, DRP:

drug, and five were classified as the need for additional drug or need for review [12].

The significance $(p<0.05)$ had been observed between the polypharmacy and disease burden. The present study shows that as the disease burden getting increased, polypharmacy also increased. Estimates of the prevalence of polypharmacy vary, often because of the differences in definitions of the number of medications that must be taken to constitute polypharmacy. In our study, we considered polypharmacy as the use of five or more medications regardless of whether they are necessary or unnecessary. The present study showed that the prevalence of polypharmacy was $87.2 \%$ very close (89\%) to the study by Salih et al. [16] among Saudi medical outpatients.

\section{CONCLUSION}

The result of snowball increase in the number of medications used in coping with various elements in older adults is their increased pharmacological vulnerability. The use of medications is, in part necessary, for the treatment of multiple comorbidities, but polypharmacy is complex, and in particular, it increases the safetyrelated problems of the medications. The prevalence of polypharmacy was found to be $87.2 \%$; in the corresponding prevalence, inappropriate drug use was found to be $27.4 \%$. Our study showed a significant association between an increase in the number of comorbidities and polypharmacy $(\mathrm{p}<0.05)$. It is also well established that the increase in the number of medications also increases the DDI, which, although in our study, it did not rise into many but three ADR's. It is necessary to take these interventions into consideration as they point toward the need for setting up a reviewing system to establish a rational drug therapy, and to avoid the problems of patient compliance and inappropriate and unnecessary prescribing of drugs. The impact of polypharmacy on consequences such as the length of stay, DDI's, and DRP's was also found to be significant in the elderly population. Hence, there is a dire need to follow precautionary measures in the prescription policy in particular in older adults.

\section{FUNDING}

None.

\section{AUTHOR'S CONTRIBUTIONS}

Lakshmi Prasanna MN designed the study and performed data collection. Data analysis was performed by Aziz Unnisa and Lakshmi Prasanna. The manuscript was drafted and revised by Aziz Unnisa. 


\section{CONFLICTS OF INTEREST}

The authors declare that there are no conflicts of interest.

\section{REFERENCES}

1. Bushardt RL, Massey EB, Simpson TW, Ariail JC, Simpson KN. Polypharmacy: Misleading but manageable. Clin Interv Aging 2008;3:383-9

2. Shalini MD, Joshi MC. Study of polypharmacy and associated problems in elderly patients. Internet J Med Update 2012;7:35-9.

3. Franchi C, Cartabia M, Risso P, Mari D, Tettamanti M, Parabiaghi A, et al. Geographical differences in the prevalence of chronic polypharmacy in older people: Eleven years of the EPIFARM elderly project. Eur J Clin Pharmacol 2013;69:1477-83.

4. John NN, Udupi RH, Binu KM. Incidence of polypharmacy induced drug interaction in a tertiary care hospital. Int J Pharm Sci Res 2012;7:2119-21.

5. Robert LM, Joseph TH, Emily RH, et al. Clinical consequences of polypharmacy in elderly. Expert Opin Drug Saf 2014;13:1-11.

6. The American Geriatrics Society Beers Criteria Update Expert Panel. American geriatrics society 2015 updated beers criteria for potentially inappropriate medication use in older adults. J Am Geriatr Soc 2015;63:2227-46.

7. Prism 5 statistics guide. HJ Motulsky-Graph Pad Software; 2007.

8. Jhon NN, Kumar NA. A study on polypharmacy in senior Indian population. Int J Pharm Chem Biol Sci 2013;3:168-71.

9. Dhikav V, Mansi S, Kumar SA, Singh AK. Polypharmacy and use of potentially inappropriate medications in patients with dementia and mild cognitive impairment. Asian J Pharm Clin Res 2014;7:218-20.

10. Harugeri A, Joseph J, Parthasarathi G, Dip G, Ramesh M, Guido S. Prescribing patterns and predictors of high-level polypharmacy in the elderly population: A prospective surveillance study from two teaching hospitals in India. Am J Geriatr Pharmacother 2010;8:271-80.

11. Jesus D, Mercedes G. Excessive polypharmacy, and survival in polypathological patients. Eur J Clin Pharmacol 2015;71:733-39.

12. Mizokami F, Koide Y, Noro T, Furuta K. Polypharmacy with common diseases in hospitalized elderly patients. Am J Geriatr Pharmacother 2012;10:123-8.
13. Nobili A, Merengoni A, Tettamanti M, Salerno F, Pasina L, Franchi C, et al. Association between clusters of diseases and polypharmacy in hospitalized elderly patients: Results from the REPOSI study. Eur J Intern Med 2011;22:597-602.

14. Díez-Manglano J, Barquero-Romero J, Mena PA, Recio-Iglesias J, Cabrera-Aguilar J, López-García $\mathrm{F}$, et al. Polypharmacy in patients hospitalised for acute exacerbation of COPD. Eur Respir J 2014;44:791-4.

15. Nobili A, Licata G, Salerno F, Pasina L, Tettamanti M, Franchi C, et al. Polypharmacy, length of hospital stay, and in-hospital mortality among elderly patients in internal medicine wards. The REPOSI study. Eur J Clin Pharmacol 2011;67:507-19.

16. Salih BS, Yousuf M, Durihim H, Almodaimegh H, Ntamim H. Prevalence and associated factors of polypharmacy among adult Saudi medical outpatients at a tertiary care center. J Fam Community Med 2013;20:162-7.

17. Ayesha R, Laxminarayana K, Astha S, Sushma M, Jayanthi CR. Polypharmacy leading to adverse drug reactions in elderly in a tertiary care hospital. Int J Pharm Bio Sci 2012;3:218-24.

18. Veena DR, Padma L, Sapna P. Drug prescribing pattern in elderly patients in a teaching hospital. Drug prescribing pattern in elderly patients in a teaching hospital. IOSR J Dent Med Sci 2012;1:39-42.

19. Chowta MN, Adhikari PM, Raj M, Laxman A, Kariappa J, George J, et al. Evaluation of appropriateness of prescription and polypharmacy in the geriatric population: A cross sectional study at a comprehensive geriatric clinic in a tertiary care hospital. Int $\mathrm{J}$ Pharm Pharm Sci 2016;8:119-23.

20. Corsonello A, Pedone C, Corica F, Incalzi RA. Polypharmacy in elderly patients at the discharge from the acute care hospital. Ther Clin Risk Manage 2007;3:197-203.

21. Siddarama R, Bharath NJ, Joshisree KP, Sahithi V. Polypharmacy induced drug interactions, adverse drug reactions (ADR) and medication errors in tertiary care South Indian hospital. Int J Pharm Pharm Sci 2019;11:88-93.

22. Sari SP, Darajat AF, Nursanti B. Drug interactions among patients with hypertension taking angiotensin converting enzyme inhibitors in an Indonesian hospital. Int J Appl Pharm 2018;10:138-41. 